\title{
Validation of a New Biomarker in Patients with Kawasaki Disease Identified by Proteomics
}

\author{
Rie Karasawa1*, Mikiya Fujieda², Kazuhide Ohta ${ }^{3}$ and Kazuo Yudoh
}

${ }^{1}$ Department of Frontier Medicine, Institute of Medical Science, St. Marianna University School of Medicine, Kawasaki, Japan ${ }^{2}$ Department of Pediatrics, Kochi Medical School, Nankoku, Japan

${ }^{3}$ Department of Pediatrics, Kanazawa Medical Center, Kanazawa, Japan

Systemic vasculitis is a heterogeneous disorder characterized by chronic or acute inflammation, and is classified into groups by the size of the affected blood vessels: large vessel vasculitis, medium vessel vasculitis, or small vessel vasculitis. The pathogenesis of systemic vasculitis is not yet understood and except for Anti-neutrophil Cytoplasmic Antibodies (ANCA) for a subset of small vessel vasculitis, biomarkers for diagnosis and disease activity in systemic vasculitis have still to be discovered. Kawasaki Disease (KD) is an acute systemic vasculitis of infancy and early childhood. It mainly affects small and medium size blood vessels, and can cause cardiovascular complications like coronary artery aneurysm.

Anti-endothelial Cell Antibodies (AECA) have been detected in a variety of diseases associated with vascular injury,and $\mathrm{KD}$ is one of them. Further, the presence of AECA has been correlated with disease activity, and/or its clinical manifestations [1,2]. A number of mechanisms for AECA, for example, activation and apoptosis of vascular Endothelial Cells (ECs), have been proposed [3]. In KD patients, IgM AECA mediate complement-dependent cytotoxicity against Human Umbilical Vein Endothelial Cells (HUVEC) and gammaglobulin, a standard therapy for $\mathrm{KD}$, may reduce their effect [4]. Grunebaum et al. [5] demonstrated that AECA increased the secretion of Interleukin-6 (IL-6) from HUVEC, in KD patients. However, a significant role for AECA in systemic vasculitis has yet to be found. To evaluate the roles of AECA in detail, it is essential that their target antigens are identified and that the role of individual target antigens is assessed. Various approaches, such as expression libraries and proteomic, have been developed to identify biomarkers [6-11]. In KD, two target antigens for the AECA, tropomyosin and T-plastin, were identified using serological analysis of a recombinant cDNA expression library [11]. However, target antigens suitable for clinical applications, including Myeloperoxidase (MPO) and proteinase 3 of ANCA, remain to be discovered.

Proteomics is a powerful tool for detecting and identifying biomarker proteins, because proteomics techniques allow the global analyses of protein function, modifications, composition and dynamics to be performed. In addition, current proteomic techniques can be used to analyze several samples from, for example, serum, urine, cerebrospinal fluid, and various tissues and cells. These kinds of analyses may lead to clinical applications. To identify the target proteins for AECA in patients with vasculitis, we used a proteomics approach that included 2-dimensional electrophoresis and Western Blotting, followed by mass spectrometry [9]. Briefly, we extracted the proteins from HUVEC and HeLa cells (control), and separated them by 2-dimensional electrophoresis to detect AECA antigens specific for ECs. We then analyzed the antigens by Western Blotting against serum samples from patients with vasculitis. We selected the spots that were detected only in the HUVEC samples, and not in HeLa cell samples. This procedure should identify candidate antigens, specific for ECs. We identified the detected proteins by peptide mass fingerprinting. Currently, we have detected more than 150 candidate antigenic spots, and identified more than 50 protein spots. In our earlier study, we identified Peroxiredoxin-2 (Prx2), a member of the Peroxiredoxin (Prx) family of peroxidases, as a target antigen for AECA [9]. In mammalian cells, the Prx family has at least six members (Table 1), and Prx2 is one of the most rapid and potent responders to oxidative stress. Furthermore, oxidative stress has been implicated as a pathogenic factor, and/or a progression-related factor in various diseases, including vasculitis. For these reasons, Prx2 was selected for further investigation. We investigated the clinical significance of anti-Prx2 antibodies in patients with KD. The titers of IgG antibodies to recombinant Prx2 were evaluated by ELISA (Enzymelinked Immunosorbent Assay), using 30 untreated patients with KD, including three patients with Coronary Artery Lesions (CALs), and 15 age- and sex-matched controls. The optical density value of the average \pm 2 Standard Deviations (SDs) in the control individuals was defined as $100 \mathrm{AU}$, and values more than $100 \mathrm{AU}$, were regarded as positive. IgG antibodies to recombinant Prx2 were detected in 60\% (18 of 30) of the untreated patients with $\mathrm{KD}$, whereas no IgG antibodies were detected in the control individuals (Figure 1). We also evaluated the titers of IgM and IgA antibodies to recombinant Prx2 by ELISA, in patients with $\mathrm{KD}$ and in controls. IgM antibodies to recombinant Prx2 were

\begin{tabular}{|c|c|c|c|}
\hline Subfamily & Active site type & Sequence length & Subcellular location \\
\hline Peroxiredoxin-1 & Typical 2-Cys & $199 \mathrm{AA}$ & $\begin{array}{l}\text { Cytosol, nucleus, } \\
\text { peroxisome, } \\
\text { mitochondria, } \\
\text { endoplasmic reticulum, } \\
\text { exosome, phagosome }\end{array}$ \\
\hline Peroxiredoxin-2 & Typical 2-Cys & $198 \mathrm{AA}$ & $\begin{array}{l}\text { Cytosol, membrane, } \\
\text { mitochondria, nucleoli }\end{array}$ \\
\hline Peroxiredoxin-3 & Typical 2-Cys & $256 \mathrm{AA}$ & $\begin{array}{l}\text { Mitochondria, cytosol, } \\
\text { nucleus, microsome, } \\
\text { early endosome, }\end{array}$ \\
\hline Peroxiredoxin-4 & Typical 2-Cys & $271 \mathrm{AA}$ & $\begin{array}{l}\text { Cytosol, endoplasmic } \\
\text { reticulum, mitochondria }\end{array}$ \\
\hline Peroxiredoxin-5 & Atypical 2-Cys & $214 \mathrm{AA}$ & $\begin{array}{l}\text { Mitochondria, cytosol, } \\
\text { peroxisome, nucleus, } \\
\text { cytoplasmic vesicle }\end{array}$ \\
\hline Peroxiredoxin-6 & 1-Cys & $224 \mathrm{AA}$ & $\begin{array}{l}\text { Cytosol, mitochondria, } \\
\text { peroxisome, lysosome }\end{array}$ \\
\hline
\end{tabular}

Table 1: Members of the peroxiredoxin family in mammals.

*Corresponding author: Rie Karasawa, Department of Frontier Medicine Institute of Medical Science, St. Marianna University School of Medicine, Kawasaki, Japan, Tel: +81-44-977-8111 (ext. 4012); Fax: +81-44-976-6401; E-mail: r2karasawa@marianna-u.ac.jp

Received December 24, 2012; Accepted January 25, 2013; Published January 31, 2013

Citation: Karasawa R, Fujieda M, Ohta K, Yudoh K (2013) Validation of a New Biomarker in Patients with Kawasaki Disease Identified by Proteomics. J Data Mining Genomics Proteomics 4: 124. doi:10.4172/2153-0602.1000124

Copyright: (c) 2013 Karasawa R, et al. This is an open-access article distributed under the terms of the Creative Commons Attribution License, which permits unrestricted use, distribution, and reproduction in any medium, provided the original author and source are credited. 


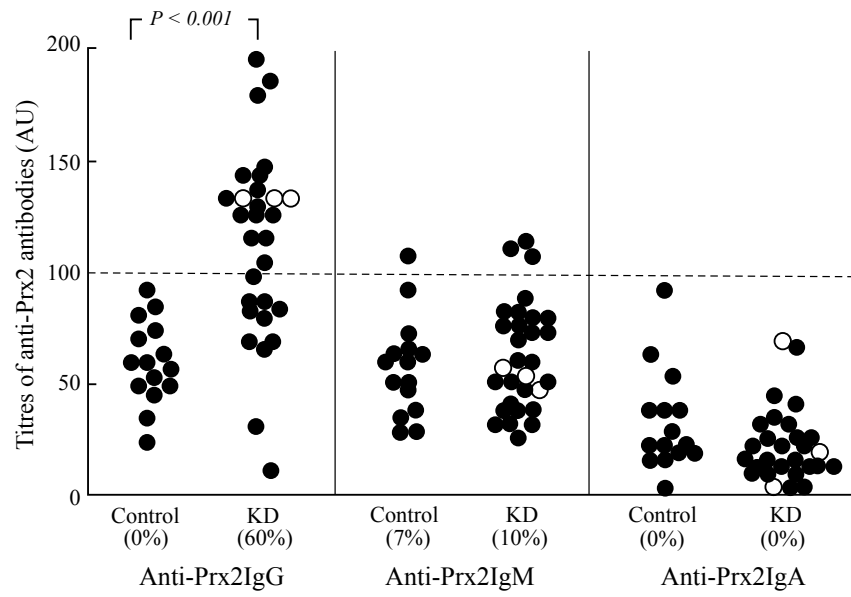

Figure 1: Titers of the peroxiredoxin-2 (Prx2)-specific IgA, IgG, and IgM antibodies in patients with Kawasaki Disease (KD). Serum samples diluted 1:200 were reacted with Prx2. The numbers in parentheses indicate the percentages of anti-Prx2 IgG-, anti-Prx2 IgM-, or anti-Prx2 IgA-positive serum samples in KD patients and control individuals. The dotted line indicates the $100 \mathrm{AU}$ cutoff lines. Open circles represent the cases with Coronary Artery Lesions (CALs). Fisher's exact test was conducted for comparison of frequency of anti-Prx2 antibodies between the control and KD groups.

detected in $10 \%$ (three out of 30 ) of the KD patients, and in $7 \%$ (one out of 15) of the controls (Figure 1). IgA antibodies to recombinant Prx2 were not detected in either group (Figure 1). Functionally, the antiPrx2 antibodies significantly increased various inflammatory cytokine secretions, in particular, IL-6 in HUVEC, and granulocyte colonystimulating factor in Human Coronary Artery Endothelial Cells (HCAEC), and induced increased expression of adhesion molecules, such as E-selectin and intercellular adhesion molecule-1. The addition of anti-Prx 2 antibodies to ECs resulted in an increased concentration of $\mathrm{H}_{2} \mathrm{O}_{2}$ in the EC cell lysate. When tested for cytotoxicity in HCAEC, IgG antibodies to Prx2 did not induce antibody-dependent cytotoxicity or complement-dependent cytotoxicity. Anti-Prx2 antibodies also did not induce apoptosis of HCAEC. Clinically, anti-Prx2 IgG antibody titer per serum IgG level was significantly correlated with disease activity in all the tested KD patients treated with high-dose intravenous IgG. All three patients who subsequently developed CALs had IgG antibodies to Prx2 (Figure 1). In contrast, neither IgA antibodies, nor IgM antibodies to Prx 2 were detected in KD patients with CALs (Figure 1). No Myeloperoxidase-ANCA (MPO-ANCA) was detected in any of the 30 patients with KD. Fujieda et al. [12] reported that, the duration of fever $>37.5^{\circ} \mathrm{C}$ and a biomarker of oxidative stress in the urine of KD patients, were significantly correlated with anti-Prx2 antibodies [12]. They also showed that there was no significant difference in inflammatory markers-such as white blood cell count, neutrophil count and C-reactive protein between KD patients, with and without anti-Prx2 antibodies.

Autoantibodies to Prxs, including Prx1 and Prx4, have been reported in patients with various kinds of disease $[13,14]$. Therefore, we also investigated the clinical importance of IgG antibodies to the other five Prx proteins, in patients with KD. Similar to the IgG antibodies against Prx2, IgG antibody titers to recombinant Prxs were evaluated by ELISA, using 27 untreated patients with $\mathrm{KD}$, including three patients with CALs, and the 15 age- and sex-matched controls that were tested for the presence of anti-Prx 2 antibodies. The optical density value of the average \pm 2 Standard Deviations (SDs) in the control individuals was defined as $100 \mathrm{AU}$, and values more than $100 \mathrm{AU}$ were regarded as positive. IgG antibodies to recombinant Prx1, Prx3, Prx4, Prx5, and Prx 6 were detected in $0 \%, 11 \%, 0 \%, 37 \%$ and $4 \%$ of the patients in the KD group, respectively. Conversely, in the control individuals, IgG antibodies to recombinant Prx1, Prx3, Prx4, Prx5, and Prx6 were detected only in $0 \%, 0 \%, 7 \%, 7 \%$ and $0 \%$, respectively. Three KD patients who were positive for anti-Prx 3 antibodies were also positive for anti-Prx2 and anti-Prx5 antibodies. Clinically, two KD patients with CALs had antibodies against recombinant Prx5. The KD patient, who was positive for anti-Prx3, anti-Prx5, anti-Prx6, and anti-Prx2, also developed CALs. Sequence alignments of the human isoforms of the Prx proteins show that $\operatorname{Prx} 2$ shares 78\%, 65\%, 70\%, 30\%, and 31\% sequence homology with $\operatorname{Prx} 1, \operatorname{Prx} 3, \operatorname{Prx} 4$, Prx5, and Prx6, respectively.

In conclusion, IgG antibodies to Prx2 may be a useful biomarker for patients with KD. IgG antibodies to Prx2 may affect the pathophysiology of $\mathrm{KD}$, by inducing expression of endothelial adhesion molecules, inflammatory cytokine production, and inhibition of anti-oxidative activity of Prx2, by binding Prx 2 on ECs. By investigating the clinical importance of IgG antibodies to the Prx proteins (Prx1 to Prx6), the antigenicity of Prx 2 was found to be different from the other five Prx proteins. The next step, therefore, is to assess the clinical usefulness of IgG antibodies to Prx2, and to clarify the mechanisms associated with the disease in large-scale studies.

\section{References}

1. Fischer K, Brzosko M, Walecka A, Ostanek L, Sawicki M (2006) Antiendothelial cell antibodies as a risk factor of atherosclerosis in systemic lupus erythematosus. Ann Acad Med Stetin 52: 95-99.

2. Park MC, Park YB, Jung SY, Lee KH, Lee SK (2006) Anti-endothelial cell antibodies and antiphospholipid antibodies in Takayasu's arteritis: correlations of their titers and isotype distributions with disease activity. Clin Exp Rheumatol 24: S10-S16.

3. Karasawa R, Yudoh K, Ozaki S, Kato T (2011) Anti-endothelial cell antibodies (AECA) in patients with systemic vasculitis: our research using proteomics. Expert Opin Biol Ther 11: 77-87.

4. Fujieda M, Oishi N, Kurashige T (1997) Antibodies to endothelial cells in Kawasaki disease lyse endothelial cells without cytokine pretreatment. Clin Exp Immunol 107: 120-126.

5. Grunebaum E, Blank M, Cohen S, Afek A, Kopolovic J, et al. (2002) The role of anti-endothelial cell antibodies in Kawasaki disease - in vitro and in vivo studies. Clin Exp Immunol 130: 233-240.

6. Youinou $P$ (2005) New target antigens for anti-endothelial cell antibodies Immunobiology 210: 789-797.

7. Margutti $P$, Matarrese $P$, Conti $F$, Colasanti $T$, Delunardo $F$, et al. (2008) Autoantibodies to the C-terminal subunit of RLIP76 induce oxidative stress and endothelial cell apoptosis in immune-mediated vascular diseases and atherosclerosis. Blood 111: 4559-4570.

8. Lee KH, Chung HS, Kim HS, Oh SH, Ha MK, et al. (2003) Human alpha-enolase from endothelial cells as a target antigen of anti-endothelial cell antibody in Behçet's disease. Arthritis Rheum 48: 2025-2035.

9. Karasawa R, Kurokawa MS, Yudoh K, Masuko K, Ozaki S, et al. (2010) Peroxiredoxin 2 is a novel autoantigen for anti-endothelial cell antibodies in systemic vasculitis. Clin Exp Immunol 161: 459-470.

10. Shirai T, Fujii H, Ono M, Nakamura K, Watanabe R, et al. (2012) A nove autoantibody against fibronectin leucine-rich transmembrane protein 2 expressed on the endothelial cell surface identified by retroviral vector system in systemic lupus erythematosus. Arthritis Res Ther 14: R157.

11. Guilpain P, Mouthon $L$ (2008) Antiendothelial cells autoantibodies in vasculitisassociated systemic diseases. Clin Rev Allergy Immunol 35: 59-65.

12. Fujieda M, Karasawa R, Takasugi H, Yamamoto M, Kataoka K, et al. (2012) A novel anti-peroxiredoxin autoantibody in patients with Kawasaki disease. Microbiol Immunol 56: 56-61. 
Citation: Karasawa R, Fujieda M, Ohta K, Yudoh K (2013) Validation of a New Biomarker in Patients with Kawasaki Disease Identified by Proteomics. J Data Mining Genomics Proteomics 4: 124. doi:10.4172/2153-0602.1000124

Page 3 of 3

13. Karasawa R, Ozaki S, Nishioka K, Kato T (2005) Autoantibodies to peroxiredoxin I and IV in patients with systemic autoimmune diseases. Microbiol Immunol 49 $57-65$
14. Iwata Y, Ogawa F, Komura K, Muroi E, Hara T, et al. (2007) Autoantibody against peroxiredoxin $\mathrm{I}$, an antioxidant enzyme, in patients with systemic sclerosis: possible association with oxidative stress. Rheumatology (Oxford) 46: $790-795$ 